\title{
Metodologias Ativas em Estatística: relato de experiência em práticas com tratamento da informação
}

\author{
Elvis Medeiros de Melo \\ Dennys Leite Maia
}

\section{Resumo}

Os conteúdos de Estatística na Educação Básica possibilitam um trabalho com a expectativa de desenvolvimento de competências e habilidades, por parte dos alunos, adequadas para a interpretação de dados estatísticos que ocorrem em seu cotidiano. Práticas que utilizem metodologias ativas no ensino desse conteúdo se fazem necessárias. O presente artigo tem o objetivo de analisar práticas pedagógicas em Estatística com metodologias ativas, baseadas no Arco de Maguerez. Abordaremos algumas das sequências didáticas que foram aplicadas no primeiro semestre de 2018 nas turmas do Núcleo de Aprofundamento de Estudos (NAE), de uma escola particular de Natal/RN, nas quais utilizamos as metodologias ativas, possibilitando que o aluno seja protagonista de sua aprendizagem. Participaram desta pesquisa cerca de mil alunos dos anos finais do Ensino Fundamental. Entre os resultados, observamos o engajamento dos estudantes na realização das atividades de Rotação em Estações de Aprendizagem e na proposta de elaboração de questionários colaborativos para coleta de dados com suporte de Tecnologias Digitais de Informação e Comunicação, propostas das metodologias ativas. Atividades como essa contribuem para potencializar a aprendizagem estatística dos estudantes, colocando-os como agentes ativos de sua aprendizagem.

Palavras-chave: Tratamento da Informação; Metodologias Ativas; Ensino de Estatística. 


\title{
Active Methodologies in Statistics: report of experience in practices with information processing
}

\author{
Elvis Medeiros de Melo \\ Dennys Leite Maia
}

\section{Abstract}

The Statistics contents at Basic Education should be worked with the expectation that students are able to develop appropriate skills suitable for the statistical data interpretation that occur in their daily lives. Practices that use active methodologies in teaching this content make it necessary. The present paper has the objective of analyzing pedagogical practices in Statistics with active methodologies, based on the Arch of Maguerez. We will cover some of the didactic sequences that were applied in the first half of 2018, at the Studies Deepening Nucleus (NAE) classes, of a Natal/RN private school, in which we use the active methodologies, placing the students as the protagonist of their learning. About one thousand students from the final years of Elementary School participate to this research. Among the results, we observed the engagement of students in the Rotation in Learning Stations and the proposal of elaboration of collaborative questionnaires for data collection with support of Digital Information and Communication Technologies, proposals of the active methodologies. Activities such as this contribute to enhancing students' statistical learning, putting them as active agents of their learning.

Keywords: Information Treatment, Active Methodologies, Statistical Learning. 


\section{Introdução}

Tornar as aulas de Estatística mais atrativas no cotidiano das aulas de Matemática é um desafio. Na Educação Básica os conteúdos de Estatística necessitam ser trabalhados com a expectativa de que os alunos sejam capazes de desenvolver competências e habilidades adequadas para a interpretação de dados estatísticos que ocorrem em seu cotidiano (BRASIL, 2017). Entretanto, infelizmente, tais conteúdos são transmitidos, assim como os demais, o que leva os alunos a conceberem a Estatística apenas como números, fórmulas, sem um contexto em que possam aplicar os conhecimentos adquiridos (DAMIN, 2015).

Enquanto que em um modelo tradicional de ensino os professores eram vistos pela sociedade como detentores do conhecimento, transmissores de saberes oficialmente constituídos, atualmente, os docentes podem atuar como mediadores no processo de aprendizagem (GIORDANO; SILVA, 2017). Para tanto, faz-se necessário uma mudança de paradigma educacional. Como destaca Morán (2015), a educação é cada vez mais híbrida com atividades presenciais e a distância - precisamos de novas estratégias para integração dos discentes às aulas. Nesse sentido, as metodologias ativas aparecem com propostas para deixar o aluno mais ativo em sala de aula, interagindo com colegas e diferentes tecnologias para a colaboração e construção dos conceitos.

Um professor preparado e consciente de que ele precisa adequar sua aula para a geração de nativos digitais (PRENSKY, 2001), faz com que sua proposta didática seja uma ponte entre conhecimento e o aluno na mediação em práticas com metodologias ativas. Bardy et al (2007, p. 94) defendem que, o professor deve assumir o papel de estimulador, mediador que coordena as discussões das ideias que vão sendo construídas, instigando os alunos a novas descobertas a partir da interação com colegas e com as Tecnologias Digitais de Informação e Comunicação (TDIC).

Castro-Filho et al (2016, p. 14) destacam que "[...] um conceito matemático pode influenciar o desenvolvimento de ferramentas tecnológicas, mas posteriormente pode ser influenciado por essa mesma tecnologia”. Quando trabalhamos com conceitos estatísticos, temos que levar em consideração que as tecnologias podem influenciar e dar significado a essa construção. Para eles, o acesso a diferentes fontes de informação, as múltiplas formas de representar o pensamento matemático, a manipulação dinâmica de símbolos matemáticos são alguns dos elementos que favorecem o pensamento estatístico apoiado por TDIC.

Em meio aos avanços tecnológicos, o professor não perde o seu papel principal, não deixa de ter relevância como mediador de aprendizagem, pelo contrário, passa a ser o agente principal do processo de ensino, por usufruir das TDIC como recursos didáticos desenvolvendo e contribuindo à prática educativa. As metodologias ativas são apoiadas pelas 
TDICs, especialmente quando falamos da Estatística (CASTRO et al, 2016), pois elas ajudam os alunos tanto na coleta quanto na análise de dados.

No âmbito do Núcleo de Aprofundamento de Estudos (NAE), a proposta da disciplina Estatística é entrar como agente problematizador dos dados obtidos durante as pesquisas de iniciação científica dos alunos por meio do Tratamento da Informação. Esse projeto faz parte do currículo acadêmico de uma escola da rede particular de Natal/RN, e acontece durante o contra-turno de aulas. As sessões acontecem a cada quinze dias, ou seja, em uma semana temos aulas com os $8^{\circ}$ e $6^{\circ}$ anos e na outra semana, aulas com os $7^{\circ}$ e $9^{\circ}$ anos, em esquema de rodízio.

O presente artigo tem o objetivo de analisar práticas pedagógicas em Estatística baseadas em metodologias ativas. Abordaremos algumas das sequências didáticas que foram aplicadas no primeiro semestre de 2018 nas turmas do NAE, nas quais utilizamos as Metodologias Ativas, colocando o aluno como protagonista de sua aprendizagem. Participaram dessa pesquisa alunos dos anos finais do Ensino Fundamental, sendo: cinco turmas de $9^{\circ}$ ano, quatro de $8^{\circ}$ ano, cinco turmas de $7^{\circ}$ ano e cinco de $6^{\circ}$ ano, totalizando aproximadamente mil alunos. Uma prática replicada para o $6^{\circ}$ e $7^{\circ}$ anos será discutida, assim como uma prática replicada para os $8^{\circ}$ e $9^{\circ}$ anos. Cada aplicação durou uma hora-aula.

Esse relato está estruturado em, além desta introdução, uma seção para fundamentação teórica a respeito do Tratamento da Informação e experiências na área utilizando metodologias ativas; descrição da metodologia do NAE e das práticas; resultados e discussões acerca das experiências; algumas considerações e indicações de trabalhos futuros; e referências consultadas.

\section{A literatura sobre tratamento da informação na educação básica}

O Tratamento da Informação é um conhecimento social explorado por todos os tipos de mídia e pela interdisciplinaridade, visto que pode proporcionar ao estudante uma ligação entre os componentes curriculares apresentados e a Matemática, que serve como ilustradora dos dados. No Brasil, a Educação Estatística está atrelada ao bloco de conteúdo Tratamento da Informação, segundo os Parâmetros Curriculares Nacionais (PCN) de 1997 e agora, na Base Nacional Comum Curricular (BNCC), publicada em 2017, na unidade temática Probabilidade e Estatística. Entretanto, a ênfase nas aulas de Matemática tem estado nas tabelas, gráficos e alguns cálculos com medidas de posição (LOPES; CARVALHO, 2009).

Pesquisas como Ainley, Nardi e Pratt (2000), Magina e Santos (2008) e Castro et al (2011) revelam que o estudo de gráficos com auxílio do ambiente computacional contribui para a aprendizagem de conceitos estatísticos. Conforme essas pesquisas, as TDIC, na 
maioria das vezes, auxiliam na visualização e exploração de um conjunto de atividades, propiciando novas formas de pensar e agir matematicamente.

De acordo com Magina e Santos (2008), o uso da tecnologia pode incrementar as relações entre educadores e crianças, políticas e educação, contribuindo para aquisição de conhecimento como relevante fator da melhoria social, proporcionando expressões multiculturais e integração universal dos indivíduos. O trabalho de Castro e Castro-Filho (2012), que explorou habilidades do Tratamento da Informação, mostrou um ambiente promissor para a realização de atividades interdisciplinares e produção de conteúdo, viabilizando a liberdade produtiva das crianças que desenvolveram a capacidade argumentativa. De acordo com os dados da pesquisa, a experiência de uso das TDICs para a aprendizagem do Tratamento da Informação ampliou os procedimentos e estratégias de coleta, organização de dados e comunicação, além de desenvolver o senso crítico, a autonomia, a criatividade e a leitura, o que favoreceu a análise e a interpretação de textos, imagens e gráficos. Isso foi oportunizado pela mobilidade proporcionada pelos laptops, utilizados no modelo 1:1 (um dispositivo por aluno) que permitiu o uso de Objetos de Aprendizagem (OA).

Para avaliar as habilidades e competências matemáticas, a Prova Brasil classifica os itens de suas avaliações de acordo com descritores e habilidades. Para a Matemática, os descritores são apresentados em quatro grandes temas de conteúdos, entre eles o Tratamento da Informação. A BNCC apresenta em seu escopo a Estatística e Probabilidade, classificando mais detalhadamente as competências e habilidades para esse tema. Avaliando práticas de Tratamento da Informação com suporte de tecnologia, descreveremos alguns trabalhos no âmbito nacional encontrados.

Os PCN (BRASIL, 1997) defendem seu ensino por meio do desenvolvimento integrado dos conhecimentos. Constata-se a necessidade de um trabalho mais efetivo com os gráficos, relacionando o Tratamento da Informação, o conhecimento diário e a Matemática, além de outros conhecimentos curriculares como Ciências, Língua Portuguesa, Geografia, História, dentre outros. Aguiar (2008) afirma que:

O uso das novas tecnologias propicia trabalhar em sala de aula com investigação e experimentação na Matemática, considerando que permite ao aprendiz vivenciar experiências, interferir, fomentar e construir o próprio conhecimento. $\mathrm{O}$ aluno participa dinamicamente da ação educativa através da interação com os métodos e meios para organizar a própria experiência. A participação do professor como facilitador do processo ensino-aprendizagem é relevante para permitir que o aluno desenvolva habilidades e seja capaz de realizar a atribuição de significados importantes (AGUIAR, 2008, p. 63). 
Quando o aluno tem contato com práticas que utilizam as TDIC como auxiliares no processo de ensino, acabam potencializando o processo de aprendizagem, segundo o autor. Na proposta deste relato, sugerimos que os alunos produzissem gráficos de colunas por meio de uma prática de estações de aprendizagem e elaborassem questionários de forma colaborativa, com suporte de tecnologia.

Conforme apontam Costa, Melo e Maia (2017), OA encontrados em seu estudo para o Tratamento da Informação, especificamente da Estatística, acabam trazendo atividades muito específicas para um determinado nível de ensino, não sendo contemplados pelas matrizes de referências de avaliação da Educação Básica. Tal característica dificulta que os OA contribuam de forma mais efetiva para o estudo de Tratamento da Informação.

Andrade e Rodrigues (2016) apresentam um portal denominado "Vem Aprender: Educação Estatística” com vários OAs interativos, projetado para facilitar o processo de aprendizagem dos alunos, com um recurso tecnológico potencialmente válido para o ensino de Matemática, em especial, do conteúdo de Estatística na Educação Básica. O "Vem Aprender" apontou melhorias no processo de ensino e aprendizagem dos alunos, pois além da seleção do material utilizado, apresentou conteúdos mais interativos e, com isso, a princípio, estimulou o interesse do aluno em querer aprender. O portal auxiliou, de fato, na compreensão do conteúdo de Estatística. Essas conclusões foram concretizadas com dezesseis alunos do Ensino Fundamental e Médio de uma Escola Estadual localizada em Minas Gerais.

Em outra proposta de recurso para o estudo dos conteúdos do Tratamento da Informação, "Esquadrão Graphics: em repórter por um dia”, é um OA idealizado por Silva et al (2015) destina-se às aulas de Matemática, mas tem potencial intra e interdisciplinares proporcionadas pelos gráficos e produções textuais. Como público-alvo, têm-se os estudantes da Educação Básica, com faixa etária entre 11 e 13 anos, ou seja, do $6^{\circ}$ e $7^{\circ}$ ano do Ensino Fundamental. Na pesquisa, revelou-se a preferência pelo gênero textual HQ (História em Quadrinhos). Como resultado, têm-se um recurso com características interdisciplinares por permitir a ligação do Tratamento da Informação, bloco pertencente à Matemática, de acordo com os PCNs (BRASIL, 1997), com a Língua Portuguesa, por necessitar a compreensão das características do gênero textual notícia. Não foi realizada testagem com público-alvo do OA desenvolvido, apenas pesquisa com grupo focal. Os autores concluem que o OA possibilite o desenvolvimento do espírito científico e da formação cidadã dos estudantes, colocando a Educação Matemática em diálogo com a construção da cidadania por meio de atividades intra e interdisciplinares proporcionadas por meio dos gráficos e das produções textuais.

Em uma prática similar a proposta foco deste artigo, Barberino (2016) investigou o desenvolvimento de conceitos estatísticos a partir da abordagem por meio de projetos, numa ISSN 2526-2882 
escola da rede estadual paulista. Seus sujeitos foram alunos concluintes do Ensino Médio. Para ela, ao coletar os dados e analisá-los, buscando fundamentar suas considerações finais, os alunos participam efetivamente da produção do conhecimento científico, particularmente do estatístico, elaborando dos gráficos e tabelas, familiarizando-se com a leitura de informações e aprimorando a percepção e questionamento crítico quanto à confiabilidade das mesmas. O ensino de Estatística por meio de projetos, segundo a autora, propicia ao estudante desenvolver os elementos cognitivos indispensáveis ao letramento estatístico, bem como desenvolver autonomia.

\section{Metodologia}

Com a proposta desta experiência, as sequências didáticas foram aplicadas nas turmas do NAE. Participaram dessa pesquisa alunos do $8^{\circ}$ e $9^{\circ}$ ano do Ensino Fundamental, sendo: 5 turmas de $9^{\circ}$ ano, 4 turmas de $8^{\circ}$ ano, 5 turmas de $7^{\circ}$ ano e 5 turmas de $6^{\circ}$ ano, com um total de, aproximadamente, mil alunos. No âmbito do NAE, a proposta da Estatística é entrar como agente problematizador dos dados obtidos durante as pesquisas dos alunos por meio do Tratamento da Informação. As sessões acontecem a cada quinze dias, ou seja, em uma semana temos aulas com os $8^{\circ}$ e $6^{\circ}$ anos e na outra semana, aulas com os $9^{\circ}$ e $7^{\circ}$ anos.

O NAE é uma iniciativa da escola com o objetivo de despertar nos alunos o gosto pelas disciplinas Ciências, Matemática, Química, Física, Biologia e Português. Os alunos propõem atividades de cunho científico, desenvolvem a pesquisa, escrevem artigos científicos, fazem experimentos, e os produtos da pesquisa que dura todo o ano são expostos durante o Painel Científico da escola. É uma proposta inovadora de iniciação científica na Educação Básica. A metodologia abordada nas sessões do NAE é baseada no Arco de Maguerez (BORDENAVA; PEREIRA, 1989). A Metodologia da Problematização com o Arco de Maguerez tem como ponto de partida a realidade que, observada sob diversos ângulos, permite ao estudante ou pesquisador extrair e identificar os problemas ali existentes. No esquema abaixo, podemos encontrar as etapas desta metodologia:

Figura 1. Arco de Maguerez

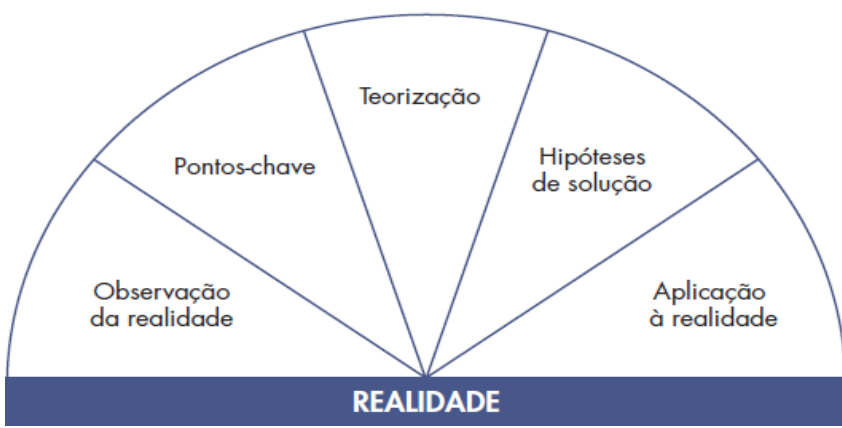

Fonte Bordenave e Pereira, 1989

ISSN 2526-2882

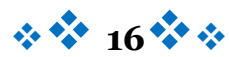


Na primeira etapa - Observação da realidade -, os alunos, com apoio do professor, analisam o contexto, identificam características e evidenciam problemas que devem ser resolvidos. Na etapa seguinte - Pontos-chaves - os sujeitos refletem sobre fatores e informações correlatos ao problema, com o objetivo de identificar e formular conceitos, questões e ideias sobre o projeto a ser empreendido. Na terceira etapa, chamada de Teorização, passa-se a construir respostas mais elaboradas, com base nas informações coletadas nas fases anteriores. Com base nisso, inicia-se a fase seguinte - Hipóteses de solução -, que demanda criatividade e pensamento crítico, alunos e professores propõem e elaboram possíveis soluções para os problemas. Na quinta e última etapa, identificada por Aplicação à realidade, é o momento da prática em que os envolvidos no projeto intervém na realidade, a partir das ideias levantadas, discutidas e analisadas anteriormente (COLOMBO; BERBEL, 2007).

Com o fortalecimento da necessidade de uma perspectiva de ensino mais voltada para a construção do conhecimento pelo aluno, essa alternativa passou a ser considerada nas últimas décadas do século XX (COLOMBO; BERBEL, 2007). A riqueza dessa metodologia está em suas características e etapas, mobilizadoras de diferentes habilidades intelectuais dos sujeitos, demandando, no entanto, disposição e esforços pelos que a desenvolvem no sentido de seguir sistematicamente a sua orientação básica, para alcançar os resultados educativos pretendidos. Essa abordagem, trabalhada de maneira interdisciplinar, pode proporcionar uma aprendizagem mais significativa dos conteúdos referentes ao Tratamento da Informação apoiados em suporte de TDIC (AINLEY; NARDI; PRATT, 2000; MAGINA; SANTOS, 2008; CASTRO et al, 2011).

Interligando as competências necessárias para o trabalho com o Arco de Maguerez, elaboramos diversas atividades que proporcionem uma aprendizagem ativa. Os alunos realizam suas atividades em grupos de 5 a 7 componentes. Para Morán (2015), é importante que atividades que envolvam metodologias ativas sejam realizadas dessa forma, pois promovem o trabalho cooperativo.

Para as aulas dos $6^{\circ}$ e $7^{\circ}$ anos foi escolhida a Rotação por Estações de Aprendizagem (REA), sendo escolhidas cinco estações. A estratégia consiste em criar uma espécie de circuito dentro da sala de aula. Cada uma das estações deve propor uma atividade diferente sobre o mesmo tema central. A ideia é que os estudantes façam um rodízio pelos diversos pontos. Cada turma é dividida em cinco grupos, e cada grupo teve de realizar cada uma das cinco atividades em cada estação. O tempo é cronometrado em sete minutos para cada estação. $\mathrm{O}$ assunto em comum para as séries foi a construção de gráficos de colunas e de barras simples $\left(6^{\circ}\right.$ anos) e de barras e colunas múltiplas ( $7^{\circ}$ ano). As atividades foram adaptadas para a linguagem adequada para cada nível. As estações foram divididas da seguinte forma: 
- Estação 1: Quebra-cabeça. Os alunos deveriam montar um quebra-cabeça que consistia num gráfico de barras e responder questões de interpretação acerca do conteúdo do gráfico, quais foram: a) Identifique de acordo com a montagem o tipo de gráfico; b) Qual(is) as informações contidas no gráfico? c) Quais os meses e o ano no gráfico que obteve maior taxa de desemprego? d) E qual foi que obteve menor taxa de desemprego? e) Qual a diferença entre a maior taxa e a menor taxa de desemprego?

- Estação 2: Situação-Problema. Os alunos recebiam uma tabela em branco e um enunciado de uma situação-problema. Em seguida, precisavam preenchê-la de acordo com os dados obtidos com a resolução do problema da bandeirada do táxi, assim como fazer generalizações para números grandes.

- Estação 3: Construção de um gráfico de colunas. Nessa estação, os alunos deveriam transformar uma tabela de entrada simples ( $6^{\circ}$ ano) ou uma tabela de dupla entrada ( $7^{\circ}$ ano) em um gráfico de colunas, utilizando papel milimetrado e canetas disponibilizadas na mesa.

- Estação 4: Interpretação de um gráfico de barras. Os alunos foram instruídos a responder diversas perguntas acerca de um gráfico de barras presente nesta estação, quais foram: a) Quantas pessoas foram entrevistadas pelo professor? b) Que tipo de lazer foi o mais escolhido? c) E o menos escolhido? d) Quantos entrevistados gostam de TV ou de cinema? e) Quantas pessoas preferem outro tipo de lazer? f) Quais os valores percentuais referentes a cada tipo de lazer do número total de entrevistados?

- Estação 5: Identificando o gráfico. Nessa estação, os alunos, assim como na anterior, deveriam interpretar o tipo de gráfico e responder algumas questões acerca de seu conteúdo, quais foram: a) Qual o tipo do gráfico? b) Qual o jogador que obteve a maior pontuação? c) Qual o jogador que obteve a menor pontuação? d) Qual a diferença entre a maior pontuação e a menor pontuação? e) Qual a soma total de pontos obtida por todos os jogadores?

Para as aulas do $8^{\circ}$ e $9^{\circ}$ anos abordaremos a prática de construção colaborativa e gamificada de questionários para levantamento de dados.

Uma prática gamificada, segundo Werbach e Hunter (2012), está baseada na utilização de elementos peculiares dos jogos digitais em outros contextos externos aos jogos, quais sejam: mecânica, ou seja, o funcionamento dos jogos; estratégias; raciocínio, com o intuito de motivar e envolver os indivíduos à prática de uma ação; resolução de um problema e promover o aprendizado de um conteúdo, habilidades ou competências.

Neste contexto, os alunos foram indicados a produzirem suas questões em relação aos conteúdos de sua pesquisa científica do trimestre. As aulas com o professor aplicador aconteceram a cada quinzena, onde os estudantes aprendem lições sobre o Tratamento da Informação e o uso da estatística para elaborarem suas pesquisas e levantamento de dados. 
No caso, a sessão teve o tema da proposta, na qual eles precisam elaborar questões de cunho objetivo para a coleta de dados.

Algumas recomendações e exigências foram feitas no momento da elaboração das questões, como por exemplo, que elas trouxessem indícios da pesquisa científica realizada por eles, ou seja, que fossem diretamente relacionadas com os seus trabalhos, além de trazer a estatística como problematizadora dos dados. Apesar de essas recomendações exigências terem sido feitas na aplicação da atividade, muitos alunos não conseguiram terminar a atividade.

A ideia proposta foi gamificada se baseou no modelo de PBL (points - pontos, badges - medalhas e leaderboards - ranqueamento). Na medida que os alunos cumpriam as atividades, receberam uma determinada quantidade de soldados, que no caso, seria a pontuação do grupo. Ao final seria gerado um ranking com a quantidade que cada grupo conseguiu. As missões distribuídas para cada grupo eram genéricas, como ilustra a Figura 2.

Figura 2. Modelo de missão dada para cada grupo na proposta.

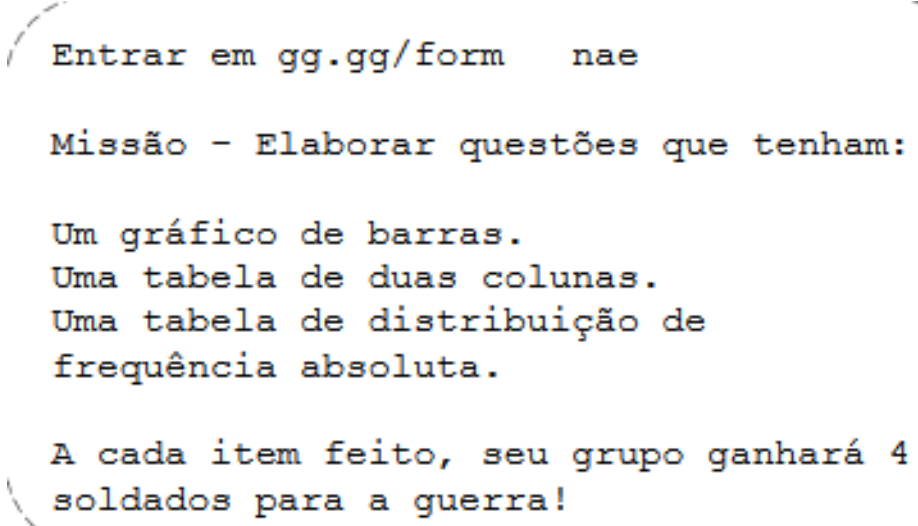

Fonte: Arquivo pessoal dos autores.

Além das missões, os alunos ganharam mais soldados realizando as seguintes atividades: (i) Elaborar 4 questões sobre os temas do grupo do NAE até agora, seguindo as recomendações de cada card (+5 soldados/questionário); (ii) Responder questionários dos outros grupos (+1 Soldado/questionário); e (iii) Responder questionário de feedback (+5 Soldados/Resposta). Esse questionário de feedback foi encaminhado para ser respondido em casa, para fins de avaliação da proposta. A ferramenta utilizada na elaboração dos questionários é o google formulários, por ser de fácil manuseio e possuir diversas ferramentas, como a geração automática de gráficos.

O papel dos participantes é bem definido nessa proposta. Para os professores: (i) definem uma temática, ou seja, esse tipo de atividade pode ser realizada em qualquer disciplina; (ii) preparam os formulários para que fiquem pré-formatados da forma como o 
professor deseja que sejam elaboradas as perguntas, quais sejam: discursivas, objetivas, de seleção múltipla, etc.; (iii) preparam os links encurtados, a fim de otimizar tempo na digitação da URL pelos alunos; (iv) avaliam as interações de cada grupo, mediando na medida do possível e gerenciando possíveis conflitos; e $(v)$ relatam suas experiências através de um questionário online. Já os alunos precisam: (i) escolher o assunto, de preferência algum assunto já estudado em sala de aula proposto pelo professor, pois a atividade tem caráter de retomada; (ii) organizam-se em grupos, para que a competência proposta pelo groupware seja colocada em ação; (iii) elaboram as questões de acordo com as orientações do professor mediador; (iv) respondem as questões dos outros grupos, a fim de gerar feedback sobre o conteúdo e o modelo das questões; e $(v)$ relatam suas experiências através de questionário online.

\section{Resultados e discussões}

$\mathrm{Na}$ aplicação do Rotação por Estações de Aprendizagem (REA), observamos o engajamento dos alunos na atividade, como ilustra a Figura 2. Essa atividade foi replicada em dez turmas, entre as quais cinco eram de $6^{\circ}$ ano e cinco de $7^{\circ}$ ano. Em cada turma, tiramos dez minutos para as orientações de como aconteceriam as atividades no dia, tirando as possíveis dúvidas para a retomada de conteúdos. Os alunos estavam sendo avaliados pela realização da atividade, assim como a cooperação com o seu grupo do NAE na proposta da REA. A experiência aconteceu em espaços de sala de aula da escola, assim como no laboratório de ensino de Matemática (Ver Figura 3).

Figura 3. Alunos interagindo nas atividades do REA.

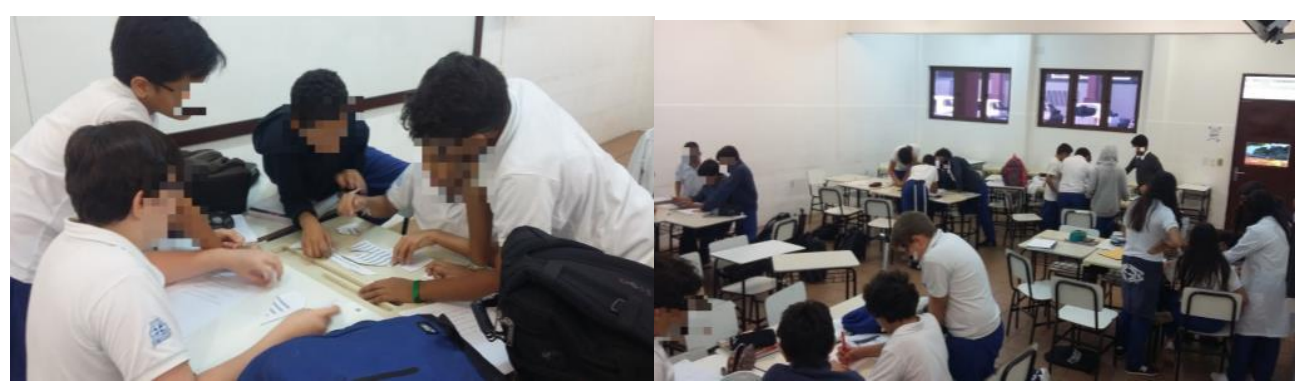

Fonte: Arquivo pessoal dos autores.

Houve colaboração no momento de realização da atividade por meio das trocas e combinados iniciais. Os alunos produziram gráficos de colunas na estação 3 e as demais atividades ficaram registradas em seus cadernos. Como o objetivo da atividade era proporcionar aprendizagem de conceitos em relação à leitura e interpretação de dados em gráficos de colunas e barras, de acordo com o feedback e produção dos alunos, avaliamos 
como exitosa, pois vários elementos do gráfico de colunas esteve presente, tais como: além de representarem os eixos cartesianos dos gráficos, os estudantes distribuíram os dados em intervalos padrões. Eles, no processo de aprendizagem, foram colocados como sujeitos ativos na realização da atividade.

Na aplicação nas turmas de $8^{\circ}$ e $9^{\circ}$ anos, foi utilizado o laboratório de informática da escola, pois a ideia seria que os alunos seguissem o modelo 1:1 (um computador por aluno). Foram distribuídos, no início da prática, papéis com os links dos formulários google compartilhados e os objetivos da elaboração das questões para cada grupo. Em momento inicial, houve um pouco de resistência no uso da ferramenta, como questões de vários usuários editando o mesmo campo de texto. Diante disso, muitos estudantes se envolveram e tiveram de organizar o grupo para o trabalho dentro do tempo estipulado. Além disso, diversos grupos optaram por designar uma pessoa para digitar o conteúdo no formulário colaborativo, além de dividir as atividades para cada componente. Aqui, a colaboração mediada por ambiente online colaborativo e fora dele foi observada em diversos grupos (Ver Figura 4).

Figura 4. Alunos interagindo dentro e fora do Espaço Virtual.

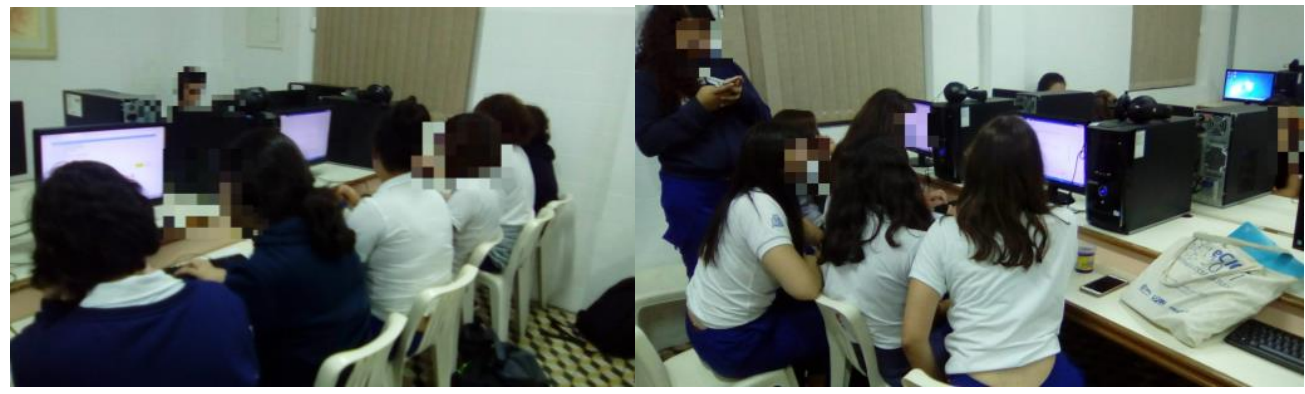

Fonte: Arquivo pessoal dos autores.

A elaboração dos questionários ajudou os alunos a desenvolverem o pensamento estatístico na medida em que problematizaram suas pesquisas científicas. A ideia era que eles utilizassem as questões elaboradas para levantar dados sobre sua pesquisa. Alguns questionamentos foram realizados para os alunos no processo de elaboração das questões: Que tipo de pergunta é mais adequada? Como a pergunta deve ser clara para que qualquer pessoa consiga entendê-la? Que tipo de dado terá como resposta? Qual o gráfico mais adequado para produção a cada tipo de pergunta?

Por mais que a ferramenta Google formulários gere gráficos automaticamente, alguns alunos construíram seus próprios gráficos a partir dos dados coletados. Quando o aluno gerou dados, através da coleta de informações com o questionário, e analisou as informações para sua pesquisa científica, ele foi ativo no processo de aprendizagem ISSN 2526-2882 
estatística. No decorrer de toda a atividade, percebeu-se engajamento dos grupos na realização da atividade.

Ao final das aulas, aplicamos um instrumento de avaliação da prática a fim de coletar informações da opinião dos estudantes. Entre os que responderam esse questionário, 89\% afirmaram querer que tenham mais atividades como essa, 90\% dos alunos enxergaram possibilidades acadêmicas de coleta de dados com a ferramenta, $89 \%$ julgou importante que hajam atividades colaborativas com suporte de tecnologia. Dentre as falas registradas, a mais presente foi a comunicação preliminar e distribuição de tarefas para a conclusão dos trabalhos em grupo. Poucos citaram o artifício da TDIC para o suporte dessas atividades antes de utilizar a ferramenta. Práticas como essa instigam a colaboração dentro de sala de aula, assim como o trabalho em grupo. Observamos em alguns momentos que os grupos se ajudaram para a realização da atividade.

Apesar de resistência inicial, 70\% dos estudantes alegaram já conhecer o Google formulários. 90\% julga importante que atividades colaborativas sejam desenvolvidas com o suporte de TDIC e viram como possibilidade o uso da ferramenta, apesar de no relato esse modo de trabalho colaborativo não ter aparecido com maior frequência. Em relação à questões quanto ao uso da ferramenta, os resultados sobre a utilização da ferramenta como suporte para atividade foram: $85 \%$ consideraram o uso da ferramenta satisfatória e $15 \%$ alegaram que a ferramenta ajudou um pouco.

Uma estudante citou o e-mail como forma de suporte de TDIC para práticas colaborativas. Sobre a importância dessas práticas colaborativas, os alunos julgaram a TDIC com poder de dar maior praticidade no processo de elaboração de questões, assim como a resolução destes instrumentos, dispensando a grande quantidade de papel.

Em uma escala de 1-Pouco significativa a 5-Muito significativa, 100\% dos alunos consideraram a atividade de médio para muito significativa, como ilustra o relato de um aluno:

A atividade foi muito boa pois essa possibilidade de usarmos a tecnologia como ferramenta em sala de aula [..] Tive algumas dificuldades na elaboração de algumas perguntas no formulário do meu grupo [...] espero que essa ferramenta seja mais usada na sala de aula.

O uso de formulário online ajudou os grupos a trabalharem em colaboração para elaboração das questões. A partir da opinião do aluno, é recomendável que se utilize e dissemine o uso das TDICs em práticas com Estatísticas e, quiçá, de outras áreas.

Em relação ao ambiente gamificado criado, perguntamos aos alunos questões de motivação ao participar de práticas que geram um ranking ao final. O resultado está ilustrado no Gráfico 1. 
Gráfico 1. Motivação dos alunos ao participar de prática gamificada.

Indif erente

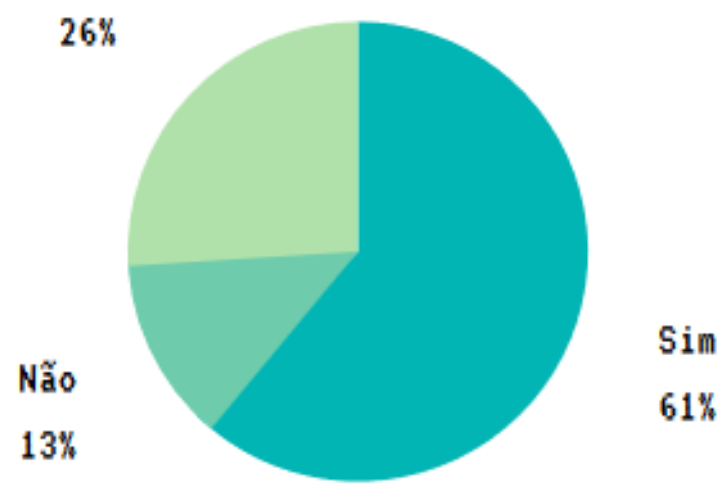

Fonte: Arquivo pessoal dos autores.

Por mais que práticas gamificadas sejam utilizadas para o engajamento dos alunos, a gamificação por meio de PBL nesse caso teve um resultado satisfatório, haja vista que $87 \%$ não opinaram negativamente para a proposta.

\section{Considerações}

Observamos, durante a aplicação da atividade, a dificuldade de elaborar as questões, assim como a satisfação por conhecer ou utilizar uma ferramenta de auxílio na elaboração das atividades de suas pesquisas científicas. As TDIC, no processo de elaboração das questões, assim como coleta de dados, tiveram papel chave, colocando assim o aluno como centro de sua aprendizagem estatística. O componente gamificado mostrou-se interessante na medida em que os grupos competiram para conseguirem a quantidade de soldados, assim como colaboração entre grupos no momento de elaboração das questões e manuseio da ferramenta digital. Seu uso potencializou o ensino mediado por TDIC.

Houve também uma grande interação e satisfação na aplicação da REA, uma proposta das Metodologias Ativas adaptada para o ensino de estatística. As adaptações foram realizadas e aspectos da estatística e do tratamento das informações dadas foram observados nas respostas dos alunos, assim como nas suas construções durante as estações.

No geral, os feedbacks foram positivos, como mostraram os resultados anteriormente comentados através das respostas dos alunos. Aspectos específicos de colaboração foram observados, quais sejam: Resolução de Problemas; Trabalho em Equipe e Coordenação. Práticas como as que abordamos neste artigo são usuais no âmbito do NAE, e pretendemos compartilhá-las em próximos trabalhos. 


\section{Referências}

AGUIAR, E.V.B. As novas tecnologias e o ensino-aprendizagem. Revista Vértices, v.10, n.1/3, jan./dez. 2008.

AINLEY, J.; NARDI, E.; PRATT, D. Towards the construction of meaning for trend in Active Graphing. International Journal of Computers for Mathematical Learning. 5.2, 2000, p.85-114.

ANDRADE, G.; RODRIGUES, C. Objetos de aprendizagem na educação estatística: "Vem Aprender”. In: V Congresso Brasileiro de Informática na Educação (CBIE 2016). Anais..., 2016.

BARBERINO, M.; MAGALHÃES, M. Uma proposta para desenvolver o letramento estatístico através de projetos. VIDYA, v. 36, n. 2, p. 363-375, 2016.

BORDENAVE, J.; PEREIRA, A. Estratégias de ensino aprendizagem. 4.ed. Petrópolis: Vozes, 1989.

BRASIL. Parâmetros curriculares nacionais: Matemática. Brasília: MEC/Secretaria de Educação Fundamental, 1997.

BRASIL. Prova Brasil: Ensino fundamental - matrizes de referência, tópicos e descritores. In: BRASIL. PDE: Plano de Desenvolvimento da Educação. Brasília: MEC/SEB/Inep, 2011.

BURDEN, K. et al. iPad Scotland evaluation. University of Hull, 2012.

CASTRO et al. Objetos de Aprendizagem digitais como suporte para a construção e compreensão de gráficos. In: CONFERÊNCIA INTERAMERICANA DE EDUCAÇÃO MATEMÁTICA (XIII CIAEM), Anais.... Recife: Edumatec/UFPE, 2011.

CASTRO, J.; CASTRO-FILHO, J. Projeto Um Mundo de Informações: integração de tecnologias digitais ao currículo escolar. In: WORKSHOPS DO CONGRESSO BRASILEIRO DE INFORMÁTICA NA EDUCAÇÃO (CBIE 2012): WORKSHOP SOBRE FORMAÇÃO E EXPERIÊNCIAS EDUCACIONAIS NO PROGRAMA UM COMPUTADOR POR ALUNO (WUCA), Anais.... Porto Alegre: Sociedade Brasileira de Computação, v.1., 2012, p.1-10.

CASTRO-FILHO, J.; MAIA, D.; CASTRO, J.; BARRETO, A.; FREIRE, R. Das tabuletas aos tablets: tecnologias e aprendizagem da Matemática. In: CASTRO-FILHO, J. A. et al. (Orgs.). Matemática, Cultura e Tecnologia: perspectivas internacionais. Curitiba: CRV, 2016, p.13-34.

CGI.BR. Pesquisa sobre o uso das tecnologias de informação e comunicação nas escolas brasileiras: TIC educação 2016. São Paulo: Comitê Gestor da Internet no Brasil, 2017. 
COLOMBO, A.; BERBEL, N. A Metodologia da Problematização com o Arco de Maguerez e sua relação com os saberes de professores. In: SEMANA: CIÊNCIAS SOCIAIS E HUMANAS, Anais... Londrina, v. 28, n. 2, p. 121-146, jul./dez. 2007.

COSTA, C.; MELO, E.; MAIA, D. A Inserção de Descritores de Tratamento da Informação na Classificação de Recursos Educativos Digitais de um Repositório. In: Congresso Brasileiro de Informática na Educação (CBIE 2017): XXIII Workshop de Informática na Escola (WIE 2017), Anais...., Recife: UFPE, 2017.

DAMIN, W. Ensino de Estatística para os anos finais do Ensino Fundamental. Disponível em: <https://goo.gl/Jui6hx>. Acesso em: 27 jun. 2018.

FERRARI, S. et al. SGESTAT: Software para cálculos e gráficos estatísticos: uma ferramenta computacional para o apoio do ensino-aprendizagem de Estatística. In: Congresso Brasileiro de Informática na Educação (CBIE 2014): WORKSHOPS (WCBIE 2014), Anais... 2014.

GIORDANO, C. O desenvolvimento do letramento estatístico por meio de projetos: um estudo com alunos do Ensino Médio. Dissertação (mestrado). São Paulo: Pontifícia Universidade Católica de São Paulo, 2016.

GIORDANO, C.; SILVA, D. Metodologias ativas em Educação Matemática: a abordagem por meio de projetos na Educação Estatística. Rev. Prod. Disc. Educ.Matem., São Paulo, v.6, n.2, pp. 78-89, 2017.

MORÁN, J. Mudando a educação com metodologias ativas. Coleção Mídias Contemporâneas. Convergências Midiáticas, Educação e Cidadania: aproximações jovens, v. 2, 2015 .

SANTOS, S.; MAGINA, S. Estratégias de Interpretação Gráfica de uma Professora Polivalente ao Manipular Dados no Ambiente Computacional. Revista Bolema. Rio Claro (SP), Ano 21, nº 29, 2008, pp. 157 a 174.

SILVA, L. et al. Esquadrão Graphics: em repórter por um dia. In: Congresso Brasileiro de Informática na Educação (CBIE 2015): WORKSHOPS DO IV Congresso Brasileiro de Informática na Educação (CBIE 2015), Anais... Alagoas: UFAL, 2015.

WERBACH, K.; HUNTER, D. For The Win: How Game Thinking Can Revolutionize Your Business. Filadélfia, Pensilvânia: Wharton Digital Press, 2012.

\section{Biografia Resumida}

Elvis Medeiros de Melo - Licenciado em Matemática pela Universidade Federal do Rio Grande do Norte (UFRN) e ISSN 2526-2882 
Especialista em Ensino de Ciências Naturais e Matemática pelo Instituto Federal de Educação, Ciência e Tecnologia do Rio Grande do Norte (IFRN). Aluno do Mestrado Profissional do Programa de Pós-graduação em Inovação em Tecnologias Educacionais (PPgITE). Membro do Grupo Interdisciplinar de Estudos e Pesquisas em Informática na Educação (GIIfE).

Link do Lattes: http://lattes.cnpq.br/3022328816415300

e-mail: elvismedeiros.mm@gmail.com

Dennys Leite Maia - Pedagogo pela Universidade Estadual do Ceará (UECE); Especialista em Planejamento, Implementação e Gestão de EaD pela Universidade Fluminense (UFF); Mestre em Educação pela UECE e Doutor em Educação Brasileira pela Universidade Federal do Ceará (UFC). Professor DIII da Universidade Federal do Rio Grande do Norte (UFRN), atuante no Instituto Metrópole Digital (IMD), lecionando no curso técnico em Tecnologia da Informação, no Bacharelado em Tecnologia da Informação (BTI) e no Programa de Pósgraduação em Inovação em Tecnologias Educacionais (PPgITE). Líder do Grupo Interdisciplinar de Estudos e Pesquisas em Informática na Educação (GIIfE).

Link do Lattes: http://lattes.cnpq.br/4047293288281493

e-mail: dennys@imd.ufrn.br 